\title{
A importância da interdisciplinaridade nos estudos e para a realização das pesquisas e projetos na área de desenvolvimento regional
}

Cláudio Machado Maia ${ }^{1}$ - Lígia Margarete Mallmann²

\section{Resumo}

Novas preocupações, conflitos e temas de debate em relação à problemática do desenvolvimento sustentável e do meio ambiente tornaram necessários novos paradigmas e conceitos para a análise da realidade contemporânea. Há uma demanda de profissionais treinados para integrarem esses referenciais na elaboração e aplicação de estratégias de desenvolvimento adequadas às problemátidas. Frente a essas exigências sociais de inovação intelectual, científica e pedagógica, confrontam-se verdadeiros desafios. Como traduzir as demandas da sociedade em conceitos científicos pertinentes? O que se entende por sustentabilidade, interdisciplinaridade? Como se dá nossa relação com o mundo social, natural e cultural? Que tipos de profissionais formar no quadro das universidades e que recursos pedagógicos adotar para isso? Como avaliar a qualidade dos cursos de formação e os documentos científicos produzidos por esses profissionais? Enfim, como se dá o conhecimento? O objetivo desta reflexão é lançar luz sobre o referencial teórico, propondo formas de pensamento, de pesquisa e de avaliação na área de desenvolvimento a partir dos conceitos de interdisciplinaridade e de sustentabilidade por constarem na expressão da demanda social e de parte dos cursos de Desenvolvimento, nos diversos programas de pós-graduação de caráter interdisciplinar no Brasil. Incorporando a duplicidade conceitual nas práticas e reflexões, uma nova realidade social e acadêmica que exige desenvolver formas de avaliação diferentes daquelas dos programas disciplinares, o artigo supõe formas de acompanhamento coerentes com as estruturas e funcionamentos de pós-graduações e graduações originados da discussão em torno desses conceitos. Logo, discute-se o papel da formação interdisciplinar na pesquisa acadêmica. Compreende-se a formação do profissional pesquisador como alternativa para atender à demanda real de profissionais responsáveis pelas trocas entre os

\footnotetext{
${ }^{1}$ Professor Titular da Universidade Comunitária da Região de Chapecó - Unochapecó (SC) no Programa de Pós-Graduação em Políticas Sociais e Dinâmicas Regionais. Doutor em Desenvolvimento Rural e Mestre em Desenvolvimento Regional. claudiomaia.dr@hotmail.com.br

2 Professora da Universidade Santa Cruz do Sul - Unisc (RS) e da Faculdade de Tecnologia La Salle Estrela (RS). Mestre em Desenvolvimento Regional.

ligia.mallmann@terra.com.br
} 
especialistas e pelo grau de integração real das disciplinas no interior de um mesmo projeto de pesquisa.

Palavras-chave: Interdisciplinaridade. Desenvolvimento regional. Pesquisa Interdisciplinar.

\begin{abstract}
New concerns, conflicts and themes of debate regarding the issue of sustainable regional development and environment necessitates new paradigms and concepts. There is a demand for trained professionals to integrate these benchmarks in the design and implementation of development strategies. Faced with these demands social innovation intellectual, scientific and educational, face real challenges. Anyway, how is the knowledge? This essay reflects the theoretical proposing ways of thought, research and evaluation in development from the concept of interdisciplinarity and sustainability. Incorporating duplicity conceptual practices and reflections. New social and academic demands that develop interdisciplinary forms of assessment. The papers accompanying forms consistent with the structures and workings of postgraduate and graduate originated the discussion around these concepts. Soon, we discuss the role of interdisciplinary academic research.
\end{abstract}

Keywords: Interdisciplinarity. Regional development. Interdisciplinary Research.

\title{
Introdução
}

Com o surgimento de novas preocupações, conflitos e temas de debate em relação à problemática do desenvolvimento regional sustentável e meio ambiente, tanto no âmbito nacional e internacional, tornou-se necessária a concepção de novos paradigmas e conceitos, visando à descrição e à análise da realidade contemporânea. Ao mesmo tempo, há uma demanda real de profissionais treinados para integrarem esses referenciais na elaboração e na aplicação de estratégias concretas de desenvolvimento adequadas às diversas problemáticas. Frente a essas exigências sociais de inovação intelectual, científica e pedagógica, as universidades e, mais amplamente, as instituições acadêmicas confrontam-se com verdadeiros desafios (RAYNAUT; LANA; ZANONI, 2000).

Entre esses desafios, estão a busca de respostas para as seguintes questões: Como traduzir as demandas da sociedade em conceitos científicos pertinentes? $\mathrm{O}$ que se entende por sustentabilidade? Como se conceitua o desenvolvimento sustentável? O que se entende por interdisciplinaridade? Como se dá nossa relação com o mundo social, natural e cultural? Que tipos de profissionais formar no quadro das universidades e que recursos pedagógicos adotar para isso? Como avaliar a qualidade dos cursos de formação, bem como dos documentos científicos produzidos por esses profissionais, como artigos e teses? Enfim, como se dá o conhecimento?

Esses são alguns questionamentos que devem ser feitos, nestes tempos de mudanças sociais e intelectuais, sendo necessário encontrar novas formas de atuação nesse domínio sem dar margem para improvisações. 


\section{A questão do desenvolvimento regional}

Há razões empíricas e teóricas que justificam o tratamento do assunto em torno da questão do desenvolvimento regional a partir de um enfoque interdisciplinar. É crescente o interesse na análise dos problemas regionais das formações sociais periféricas a partir da compreensão de que as desigualdades do espaço local tendem a ser agravadas pela exposição do local ao global, à globalização comandada pelas economias capitalistas centrais.

Em termos teórico-metodológicos, a crise do Estado como gestor de políticas públicas, a fragilização das fronteiras nacionais e a inserção subordinada na economia capitalista globalizada são problemas postos para os estudiosos do desenvolvimento, que não podem ser enfrentados a não ser recorrendo-se a instrumentos metodológicos desenvolvidos em várias disciplinas do conhecimento (MATTEDI; THEIS, 2002, p. 88).

Pode-se propor muitos conceitos para desenvolvimento. Entretanto, nesta reflexão, sugere-se que desenvolvimento é um processo baseado na alocação eficiente de recursos e no crescimento sustentável do produto agregado a longo prazo, promovido pelo emprego de mecanismos socioeconômicos e institucionais, visando ao incremento rápido e em larga escala dos níveis de vida das massas pobres de nações e regiões periféricas (TODARO, 1997).

Quanto ao conceito de região, associado ao de desenvolvimento sugerido, entende-se que se trata de uma localidade ou um lugar que corresponde a uma certa área geográfica de extensão subnacional. Essa área apresenta um determinado grau de desenvolvimento, associado à presença de uma dada comunidade de indivíduos - pertencentes a distintos grupos e classes sociais - e de suas atividades socioeconômicas (SCOTT, 1998; CORRÊA apud MATTEDI; THEIS, 2002).

Por outro lado, para Becker (2002, p. 88), “[...] o processo de desenvolvimento regional deixa de ser pura e simplesmente uma questão quantitativa e adquire crescentes dimensões qualitativas, através do pleno reconhecimento e do pleno desabrochar das diversidades regionais". Isso nos remete à necessidade de se medir e considerar perfis e produtividades espaciais diferentes segundo os lugares diferentes e chegar-se a processos de desenvolvimento diferentes.

Desenvolvimento é o processo localizado de mudança social sustentável, que tem como propósito último o progresso permanente de uma comunidade e de seus respectivos membros, que vivem em um determinado espaço regional (BOISIER, 1996).

Por essas explicações, vê-se que a noção de desenvolvimento regional sustentável vai além da esfera econômica. Ela inclui os aspectos como o social, o cultural, o ecológico, o territorial e o político, sendo concebida de forma coletiva, na qual os vários atores sociais (mercado, Estado e sociedade civil) interagem de forma responsável com certo nível de interesses comuns, o que exige a contribuição e reflexão de outras áreas do conhecimento para dar conta de tal complexidade.

Logo, a interdisciplinaridade pode pressupor adotar um conceito de desenvolvimento que se distancia das abordagens enviesadas por recortes monodisciplinares, tais como os derivados da ideia de aumento da riqueza das nações (como em Adam Smith e em alguns economistas clássicos) ou do crescimento econômico (como defendido pelos 
simpatizantes de Keynes) ou mesmo da acumulação de capital.

\section{A questão ambiental}

A problemática do meio ambiente começou a ser refletida nas discussões sobre desenvolvimento principalmente a partir da década de 1970, com o debate iniciado pelo relatório do Clube de Roma - Limites do Crescimento (1972). Limites do Crescimento é um documento criado por um grupo internacional com o apoio de empresas multinacionais europeias, apontando os limites do crescimento da produção, considerando o caráter finito das reservas mundiais de recursos não renováveis, especialmente dos energéticos. "Para alcançar a estabilidade econômica e ecológica, Meadows et al. (1973) propõem o congelamento do crescimento da população global e capital industrial; mostram a realidade dos recursos limitados e rediscutem a velha tese de Malthus do perigo do crescimento desenfreado da população mundial" (BRÜSEKE, 1995, p. 30).

Foi nesse contexto de noção da "crise global" (crescimento da população, degradação ambiental e limites de produtividade), durante os anos 1960 e 1970, que houve uma contribuição para a emergência da ideia de desenvolvimento sustentável na cena política internacional.

A Conferência de Estocolmo (1972) foi muitas vezes vista como o evento central da emergência da ideia de desenvolvimento sustentável, especialmente na agenda internacional. Divisões entre os países do Norte e do Sul surgiram em parte por causa da influência do neomalthusianismo e motivações duvidosas (direitos aos recursos naturais, etc.). $O$ evento foi dominado pelos interesses dos países industrializados, mas com a tentativa de incluir e convencer os países do Sul da necessidade dos acordos ambientais internacionais. Uma ideia central foi a de que os interesses do meio ambiente podem ser integrados com os programas de desenvolvimento, sem ter impactos negativos.

Também deve ser citado o Relatório Brundtland - Our Common Future (1987). A origem do evento na Assembléia Geral das Nações Unidas ofereceu mais legitimidade que os outros eventos anteriores. Incorporou elementos ao debate sobre o desenvolvimento sustentável dentro do contexto econômico e político de desenvolvimento internacional e fortaleceu a posição do tema do meio ambiente na agenda política internacional. O relatório apresentou medidas a serem tomadas em nível do Estado Nacional e em nível internacional, ambas vagas e não muito práticas. O documento não mudou a paisagem intelectual do pensamento desenvolvimentista, mas acrescentou a ideia de sustentabilidade, em uma posição longe de poderosa e com uma postura mais reformista (ADAMS, 2001; GODARD, 1997; BRÜSEKE, 1995).

No Brasil, iniciou-se, a partir de meados da década de 1970, um movimento ecológico marcante, e a questão ambiental passou a ser um assunto político (VIOLA, 1987 apud RAYNAUT; LANA; ZANONI, 2000). Com a Rio 1992 (UNCED), a ligação entre desenvolvimento socioeconômico e as transformações no meio ambiente, durante décadas ignorada, entrou no discurso oficial da maioria dos governos do mundo (BRÜSEKE, 1995). A Agenda 21 é o documento mais importante e o maior (600 páginas), entre vários outros. Ofereceu a base para vários tipos de ação em busca de 'sustentabilidade', mas não faz 
nenhum deles obrigatório. Junto com o Relatório Brundtland, construiu-se o pensamento mainstream do desenvolvimento sustentável. O documento, como o evento em geral, não concretizou o que significa desenvolvimento sustentável, não criou uma estrutura nem uma ideia de prazo para cumprir as ações, e o debate continuou com a mesma força (ADAMS, 2001; GODARD, 1997).

\section{Um novo quadro conceitual}

Conforme Raynaut, Lana e Zanoni (2000), para se compreender qualquer tipo de avaliação de uma atividade de caráter científico, tanto em termos de pesquisa quanto de formação, é necessário definir o referencial teórico e conceitual em função do qual a coerência de objetivos dos cursos será analisada. Não se trata de impor uma linha teórica hegemônica em um contexto ou área na qual muito ainda está para ser construído, mas sim de estabelecer alguns marcos comuns, de criar um consenso mínimo sobre a maneira de abordar alguns conceitos-chave. Não se trata de procurar uma definição única, mas de definição às margens de variação aceitáveis para manter critérios de avaliação comuns.

Em um esforço inicial de harmonização, duas noções básicas são prioritárias por constarem de todas as formas de expressão da demanda social, ambientalista e de qualquer curso de Desenvolvimento. São as noções de "Desenvolvimento Sustentável" e de "Interdisciplinaridade". Para todos os que se utilizam de uma perspectiva científica, é necessário um trabalho aprofundado de crítica e de esclarecimento dessas noções.

\section{Sustentabilidade}

A noção de sustentabilidade ou de durabilidade origina-se de teorizações e de práticas ecológicas que tentam analisar a evolução temporal de recursos naturais, tomando por base a sua persistência, manutenção ou capacidade de retorno a um presumido estado de equilíbrio, após algum tipo de perturbação. Mesmo no campo ecológico, essa noção de equilíbrio é um tema polêmico e controverso, já que os sistemas naturais, como por exemplo os chamados recursos não renováveis, estão sujeitos a elevada variabilidade, expressa em diversas escalas temporais e espaciais (RAYNAUT; LANA; ZANON, 2000).

Altieri (1987 apud MARCATTO, 2006) define sustentabilidade como sendo a habilidade de um agroecossistema em manter a produção através do tempo, face a distúrbios ecológicos e pressões socioeconômicas de longo prazo.

\section{Desenvolvimento sustentável}

A tentativa de incorporar o conceito de sustentabilidade às políticas públicas de desenvolvimento é relativamente recente. Até o início da década de 1970, as estratégias globais de desenvolvimento não contemplavam especificamente a problemática ambiental ou do uso continuado de seus recursos naturais, uma vez que as manifestações 
conservacionistas eram vistas como esforços contrários aos planos de desenvolvimento. A ótica era de que a natureza não representava um custo, mas existia para ser modificada e valorizada (RAYNAUT; LANA; ZANONI, 2000).

Nos anos 1970, a pauta ambiental já estava presente e era uma das principais condicionadoras da ideia de "ecodesenvolvimento". A disseminação do conceito de ecodesenvolvimento foi marcante, conforme demonstrado pelas reflexões e ações do próprio Programa das Nações Unidas para o Meio Ambiente e pela proliferação de unidades de pesquisa e teorização em todo o mundo (ZANONI; RAYNAUT, 2004 apud RAYNAUT; LANA; ZANONI, 2000).

Interdisciplinaridade

Segundo Japiassú (1976), a interdisciplinaridade caracteriza-se pela intensidade das trocas entre os especialistas e pelo grau de integração real das disciplinas no interior de um mesmo projeto de pesquisa. Para esclarecer alguns problemas de terminologia dentro da questão e do conceito de interdisciplinaridade aqui desenvolvido, e abrir caminho a uma reflexão epistemológica, Korte (2000), apresenta uma distinção terminológica, em alguns níveis de significados, a saber:

a) Disciplina: conjunto específico de conhecimentos com suas próprias características sobre o plano do ensino, da formação dos mecanismos, dos métodos, das matérias.

b) Multidisciplina: justaposição de disciplinas diversas, desprovidas de relação aparente entre elas. Exemplo: Música mais Matemática e mais História. Para Schmitz (2005), a multidisciplina funciona como um amálgama de diversas áreas de conhecimento, as quais trabalham como meras subdisciplinas sem nenhum intercâmbio.

c) Pluridisciplina: justaposição de disciplinas mais ou menos vizinhas nos domínios do conhecimento. Exemplo: domínio científico - Matemática mais Física.

d) Transdisciplina: resultado de uma premissa comum a um conjunto de disciplinas. Exemplo: Antropologia, considerada como a ciência do homem e de suas obras. Para Schmitz (2005), quando se trata de uma postura transdisciplinar, deve existir muito mais de um mero contato entre duas ou mais disciplinas. A troca transdisciplinar sugere que os pesquisadores nas diversas disciplinas no jogo discursivo vejam sua disciplina da ótica da outra. Para chegar a ser transdisciplinar, o contato ou intercâmbio precisa ser recíproco.

e) Interdisciplina: interação existente entre duas ou mais disciplinas. Essa interação pode ir da simples comunicação de ideias à integração mútua dos conceitos diretores da epistemologia, da terminologia, da metodologia, dos procedimentos, dos dados e da organização referentes ao ensino e à pesquisa. Um grupo interdisciplinar compõe-se de pessoas que receberam sua formação em diferentes domínios do conhecimento (disciplinas) com seus métodos, conceitos, dados e termos próprios. Isso sugere que, na interdisciplinaridade, existe um contato entre duas ou mais disciplinas. Esse contato se reflete nas hipóteses formuladas, na bibliografia utilizada e nas conclusões levantadas.

As categorias utilizadas para caracterizar a multi e a interdisciplinaridade, tanto por Fazenda (1995) quanto por Japiassu (1972) são as mesmas. Sugere-se a classificação 
realizada por Jantsch, em 1972, que associa a palavra 'justaposição' à multi e 'integração' à inter. Veja a Figura 1 abaixo:

MULTIDISCIPLINARIDADE
Sistema de um só nível e de objetivos
múltiplos; nenhuma cooperação.
PLURIDISCILINARIDADE
Sistema de um só nível e de objetivos
múltiplos; cooperação mas sem coordenação.
INTERDISCIPLINARIDADE
Sistema de dois nível e de objetivos
múltiplos; cooperação procedendo nivel superior.
TRANSDISCIPLINARIDADE
Sistema de níveis e
objetivos múltiplos;
coordenação com vistas a
uma finalidade comum dos
sistemas

Figura 1 - 0 modelo de Jantsck Fonte: Jantsch (1972, p. 108)

\section{Formação acadêmica}

Em época de grandes mudanças sociais e intelectuais, os velhos quadros de pensamento e os critérios e procedimento de avaliação há muito estabelecidos deixaram de atender satisfatoriamente a essas novas realidades. É necessário encontrar novas formas de atuação nesse domínio sem dar margem para improvisações. A interdisciplinaridade nos diversos cursos de pós-graduação (nível de mestrado/doutorado) vem sendo implantada no país como reação natural da comunidade universitária brasileira à dificuldade de abordagem da temática do meio ambiente e desenvolvimento a partir de posturas disciplinares de caráter linear ou reducionista, sejam elas naturalistas ou sociopolíticas. O grande mérito da maioria das pesquisas e do ensino interdisciplinares é a contínua estimulação de uma consciência da interdependência e da inter-relação entre os fenômenos sociais e a inadequação das conclusões teóricas que visualizam os problemas sob discussão a partir do ponto de vista de uma disciplina. A interdisciplinaridade 
cultiva, em cada participante, uma familiaridade com os conceitos e métodos de outra ciência (KAPP, 1961).

\section{Perfil do profissional de desenvolvimento regional}

A natureza contingente e histórica das disciplinas e das profissões não significa que elas sejam intercambiáveis, ou que as divisões e diferenças sejam irrelevantes. É no interior das disciplinas e das profissões que se estabelecem as tradições de pesquisa e de trabalho. É por meio delas que se dá a socialização das jovens gerações nos modos de pensar e proceder, que são a base sobre a qual o trabalho científico, cultural e técnico-profissional se desenvolve. O trabalho interdisciplinar é, por definição, efêmero e depende da existência prévia de pessoas formadas em disciplinas bem definidas, que, em determinados momentos, buscam conhecimentos e estabelecem formas de cooperação com pessoas de outras áreas. Se as "interdisciplinas" se desenvolvem e se consolidam, elas se transformam em novas disciplinas ou subdisciplinas, como é o caso, por exemplo, da biologia molecular, da história econômica ou da físico-química. As tentativas de constituir campos de trabalho a partir de temas, objetos ou problemas específicos, como a educação, o urbanismo, a administração e os problemas sociais, apresentam mais fracassos do que sucessos, e os sucessos que surgem dependem sempre da forte presença de pessoas com formação disciplinar bem definida em suas respectivas áreas, por exemplo, em psicologia, economia, sociologia, ciência política, ou pedagogia (SCHWARTZMAN, 1997).

Na pesquisa interdisciplinar, tende-se a reproduzir uma representação das ciências na qual cada disciplina ou domínio do conhecimento estabelece um subcampo de ação, no qual os pesquisadores desenvolvem um "habitus" que lhe é próprio e no qual poderá haver contestações ${ }^{3}$. A iniciativa de cooperação poderá ser abortada se os pesquisadores envolvidos começarem a temer a perda de sua legitimidade no campo científico, uma legitimidade tradicionalmente garantida pelos conhecimentos adquiridos e integrados por meio do capital científico ao longo de toda sua carreira.

Nessa perspectiva analítica, pode-se perceber as razões que incitam um pesquisador a enclausurar-se na "torre de marfim" de sua disciplina, em seu laboratório ou em seu grupo acadêmico e o porquê de ele ser refratário diante de toda iniciativa suscetível de ameaçar sua legitimidade e seu espaço de poder no campo científico ou domínio do conhecimento. Como reações de defesa, podem ser observadas, nas discussões acadêmicas sobre os métodos, as abordagens e as teorias empregadas para tratar um objeto de pesquisa determinado. Nessas discussões, tanto os jovens pesquisadores como os mais experimentados sentem dificuldades em se integrar em um programa dessa natureza: os primeiros não têm ainda objetivos universitários e científicos bem definidos; os segundos se recusam a flexibilizar suas certezas e suas garantias de estabilidade construídas em seu subcampo de pesquisa ou em seu domínio de conhecimento específico. Para alguns pesquisadores, o investimento na pesquisa interdisciplinar seria muito pesado, na medida em que os resultados levam muito tempo a aparecer. A esses dois grupos

${ }^{3}$ A noção de campo científico é empregada aqui segundo a concepção de Bourdieu (1983 apud ALMEIDA et al., 2004). 
de pesquisadores, os jovens e os mais experimentados, deve-se convencer e estimular a aceitação da interdisciplinaridade (ALMEIDA et al., 2004).

As posições apresentadas identificam a incompreensão do que são o trabalho e a metodologia interdisciplinar e reforçam uma perspectiva conservadora da ciência e do processo científico. O receio da perda de autonomia disciplinar, com suas teorias e métodos próprios, é destacado. Percebe-se que poderá haver uma falta de compreensão de que a interdisciplinaridade, enquanto princípio mediador de comunicação entre diferentes disciplinas, não será jamais um elemento de redução a um denominador comum, mas um elemento teórico e metodológico da diferença e da criatividade: "[...] a interdisciplinaridade é o princípio da exploração máxima das possibilidades de cada ciência ou disciplina científica, da compreensão de seus limites, mas é antes de tudo o princípio da diversidade e da criatividade" (ETGES, 1993, p. 53).

\section{Considerações finais}

A importância da resistência ao estudo e à abordagem interdisciplinar está ligada ao que Raynaut, Lana e Zanoni (2000) chamam de "processos de avaliação" acadêmica, por meio dos quais as comunidades científicas regulam seus funcionamentos, consagram filiações e estabelecem hierarquias. Esses processos são tributários das disciplinas nas quais o trabalho intelectual é realizado. Essa valoração deve receber o aval dos organismos oficiais de avaliação (como a Capes e o CNPq no Brasil) e satisfazer critérios de qualidade estabelecidos, como o nível de impacto da divulgação dos resultados das pesquisas por meio das revistas científicas de excelente nível ou a frequência das citações. É assim que são reconhecidas a qualidade e a importância da pesquisa científica e universitária.

No estudo interdisciplinar, essas exigências estão ainda longe de serem satisfeitas. A complexidade e a especificidade das situações e dos objetos analisados tornam muito difícil a reprodução das observações, além do fato agravante de que os aspectos práticos dos problemas a resolver conduzem a resultados mais absorvidos por um "uso social", não podendo ser publicados imediatamente. Por outro lado, a interdisciplinaridade não é definida previamente: ela surge a partir dos desafios de uma realidade complexa e dinâmica.

\section{Referências}

ADAMS, William Mark. Green Development: environment and sustainability in the Third World. 2nd edition. New York: Routledge, 2001.

ALMEIDA, Jalcione et al. Pesquisa interdisciplinar na pós-graduação: (Des)Caminhos de uma experiência em andamento. Revista Brasileira de Pós-Graduação, Brasília, Capes, n. 2, 2004.

BECKER, Dizimar F. Desenvolvimento Sustentável: Necessidade e/ou Possibilidade? 4. ed. Santa Cruz do Sul: Edunisc, 2002. 
BOISIER, Sergio. Modernidad y território. Santiago de Chile: ILPES, 1996.

BRÜSEKE, Franz Josef. O Problema do Desenvolvimento Sustentável. In: VIOLA, Eduardo et al. Meio Ambiente, Desenvolvimento e Cidadania: Desafios para as Ciências Sociais. Santa Catarina: Cortez, 1995.

GODARD, Olivier. O Desenvolvimento Sustentável: Paisagem Intelectual. In: Castro, Edna; Pinton, Florence (Orgs.). Faces do Trópico Úmido: conceitos e questões sobre desenvolvimento e meio ambiente. Belém: Cejup, 1997.

ETGES, Norberto J. Produção do conhecimento e interdisciplinaridade. Rumos, Brasília, caderno especial, n. 8, 1993.

FAZENDA, Ivani C. A. Interdisciplinaridade: um projeto em parceria. São Paulo: Loyola, 1995.

JANTSCH, Ari Paulo. Interdisciplinaridade: para além da filosofia do sujeito. Petrópolis: Vozes, 1972.

JAPIASSU, Hilton. Interdisciplinaridade e patologia do saber. Rio de Janeiro: Imago, 1976.

KAPP, Karl William. Toward a Science of Man in Society. A Positive Approach to the Integration of Social Knowledege. Haia: Martinus Nijhoff, 1961.

KORTE, Gustavo. Introdução à metodologia transdisciplinar. São Paulo: NEST, 2000.

MARCATTO, Celso. Agricultura Sustentável: alguns conceitos e princípios. 2006.

Disponível em: <http://www.redeambiente.org.br>. Acesso em: 11 nov. 2012.

MATTEDI, Marcos A.; THEIS, Ivo M. Cruzando fronteiras: conhecimento e interdisciplinaridade na pesquisa em desenvolvimento regional. Redes, Santa Cruz do Sul, v. 7, n. 2, p. 77-94, maio/ago. 2002.

RAYNAUT, Claude; LANA, Paulo da Cunha; ZANONI, Magda. Pesquisa e formação na área do meio ambiente e desenvolvimento: novos quadros de pensamento, novas formas de avaliação. In: Desenvolvimento e Meio Ambiente: Teoria e Metodologia em meio ambiente e desenvolvimento. Curitiba, UFPR, n. 1, p. 71-81, jan./jun. 2000.

SCHMITZ, D. Estudos disciplinares. Revista Signos, 2005. Disponível em: <http://www.abc.org.br>. Acesso em: 16 jul. 2012.

SCHWARTZMAN, Simon. A redescoberta da cultura. São Paulo: Universidade de São Paulo, 1997.

TODARO, Michel P. Economic development. 6. ed. London; New York: Longman, 1997. 